\title{
UMA INTERFACE ENTRE O EU-CORPO NA PSICANÁLISE FREUDIANA E O CORPO PRÓPRIO NA FENOMENOLOGIA DO CORPO
}

An interface between the self-body in Freudian psychoanalysis and the body itself in the phenomenology of the body

Una interfaz entre el yo-cuerpo en la psicoanálisis freudiana y el cuerpo propio en la fenomenología del cuerpo

Fabio Caprio Leite de Castro' Pontifícia Universidade Católica do Rio Grande do Sul, Porto Alegre, RS, Brasil.

Cristian Marques ${ }^{2}$

Pontifícia Universidade Católica do Rio Grande do Sul, Porto Alegre, RS, Brasil.

\section{Resumo}

O presente artigo tem por objetivo mostrar, desde a psicanálise freudiana, um caminho possível que a leva ao encontro da filosofia de orientação fenomenológica. Em O eu e o isso, de 1923, Sigmund Freud emprega uma nova noção pouco explorada na literatura psicanalítica: o eu-corpo (Körper-ich). O escopo de nossa análise delimita-se à interpretação e à explicitação da noção de eu-corpo tal como esta foi apresentada por Freud, confrontando-a com a fenomenologia em Merleau-Ponty e Michel Henry.

Doutor em Filosofia pela Université de Liège. Professor do Programa de Pós-Graduação em Filosofia da Pontifícia Universidade Católica do Rio Grande do Sul (PUCRS), Porto Alegre, RS, Brasil. ORCID: http://orcid.org/o000-0002-5156-0492. E-mail: fabio.castro@pucrs.br

2 Mestre e doutorando em Filosofia pela Pontifícia Universidade Católica do Rio Grande do Sul (PUCRS), Porto Alegre, RS, Brasil. ORCID: http://orcid.org/oooo-0002-7743-8356. E-mail: cristianmq@gmail.com 
Para tanto, propomos uma análise em quatro tempos. Inicialmente, evidenciaremos o entendimento de Freud sobre o modelo de psicologia originada em Brentano que tem como um de seus desdobramentos a fenomenologia. Depois, mostraremos como a concepção do isso, segundo o próprio texto de Freud, foi determinante para que ele formulasse uma revisão da primeira tópica e a incorporasse em uma segunda tópica. Por fim, nas últimas duas partes, examinaremos o tratamento dado por Merleau-Ponty e Michel Henry à questão do corpo. Concluímos que é possível o encontro entre a psicanálise e a fenomenologia via a noção de eu-corpo freudiano; contudo, tal condução implicará reformulações em teses centrais da psicanálise.

Palavras-chave: Eu-corpo. Corpo próprio. Psicanálise. Freud. Fenomenologia.

\begin{abstract}
This paper aims to show, since Freudian psychoanalysis, a possible path that leads it to meet the philosophy of phenomenological orientation. In 1923's The ego and the id, Sigmund Freud employs a new notion that is little explored in psychoanalytic literature: the self-body (Körper-ich). The scope of our analysis is limited to the interpretation and explicitation of the notion of self-body as presented by Freud, confronting it with the phenomenology in Merleau-Ponty and Michel Henry. Therefore, we propose a four-stroke analysis. Initially, we will highlight Freud's understanding of the model of psychology originated in Brentano, which has as one of its developments phenomenology. Then we will show how the conception of the id, according to Freud's own text, was decisive for him to formulate a revision of the first topic and to incorporate it into a second topic. Finally, in the last two parts, we will examine the treatment given by Merleau-Ponty and Michel Henry to the matter of the body. We conclude that the encounter between psychoanalysis and phenomenology is possible via the notion of Freudian self-body; However, such conduct will imply reformulations in central theses of psychoanalysis.
\end{abstract}

Keywords: Self-body. Body itself. Psychoanalysis. Freud. Phenomenology

\title{
Resumen
}

Este artículo pretende mostrar, desde la psicoanálisis freudiana, un posible camino que conduce a la filosofía de orientación fenomenológica. En El yo y el esto, y la de 1923, Sigmund Freud emplea una nueva noción poco explorada en la literatura psicoanalítica: el yo-cuerpo (Körper-ich). El alcance de nuestro análisis se delimita a la interpretación y explicación de la noción de yo-cuerpo tal como esta fue presentada por Freud, confrontando con la fenomenologia en Merleau-Ponty y Michel Henry. Para ello, proponemos 
un análisis en cuatro tiempos. Inicialmente, evidenciaremos la comprensión del modelo de la psicología freudiana sobre el modelo de psicologia originada en Brentano que tiene como uno de sus desdoblamientos la fenomenología. A continuación, le mostraremos cómo la concepción del esto, según el texto de Freud, fue decisiva para él formular una revisión de la primera tópica y en incorporarla en una segunda tópica. Por último, en las dos últimas secciones, examinaremos el tratamiento dado por Merleau-Ponty y Michel Henry la cuestión del cuerpo. Concluimos que es posible el encuentro entre el psicoanálisis y la fenomenología mediante el concepto de yo-cuerpo freudiano; sin embargo, tal conducción implicará reformulaciones en tesis centrales del psicoanálisis.

Palabras claves: Yo-cuerpo. Cuerpo propio. Psicoanálisis. Freud. Fenomenología.

\section{Introdução}

A psicanálise e a escola da fenomenologia nascem paralelamente ao final do século XIX e percorrem caminhos próprios desde então, passando por diversas teorizações e reformulações, que geraram tanto a mútua resistência entre fenomenólogos e psicanalistas, assim como o diálogo e a interação frutífera. Ainda hoje, apesar dos muitos esforços nesse sentido, remanesce a interrogação sobre a viabilidade teórica de aproximação desses dois campos.

Sem a pretensão de responder peremptoriamente a essa interrogação, o presente artigo foi concebido com o objetivo de mostrar, desde a psicanálise freudiana, um caminho possível que a leva ao encontro da filosofia de orientação fenomenológica. A hipótese que propomos é resultado da leitura de um dos textos mais marcantes da psicanálise, $O$ eu e o isso, de 1923. Nesse texto, Sigmund Freud oferece pistas sobre o que ele mesmo pensava da fenomenologia e sobre uma nova noção que ele emprega nesse texto: o eu-corpo (Körper-ich) ${ }^{3}$.

O escopo de nossa análise fica delimitado à interpretação e à explicitação da noção de eu-corpo tal como essa foi apresentada por Freud, confrontando-a com a sua abordagem na fenomenologia em Merleau-

3 FREUD, Sigmund. Das Ich und das Es. Vol. III - Studienausgabe. Frankfurt am Main: Fischer, 1975, p. 295. Tradução nossa. 
Ponty e Michel Henry. Para tanto, propomos uma análise em quatro tempos. Inicialmente, colocaremos em evidência uma pista deixada por Freud em uma nota de rodapé do primeiro item de $O$ eu e o isso que revela o seu entendimento sobre o modelo de psicologia originada em Brentano e que teve as mais diversas afluências, entre elas, a da fenomenologia.

Depois disso, mostraremos como a concepção do isso, segundo o próprio texto de Freud, foi determinante para que ele formulasse uma revisão da primeira tópica (consciente, pré-consciente e inconsciente) e a incorporasse em uma segunda tópica (isso, eu e supereu).

A introdução de uma perspectiva topológica do eu, em contato com o isso, leva Freud a formular um novo entendimento sobre o corpo. Esse será, o tema do terceiro ponto de nossa análise, no qual vamos examinar detidamente a noção de eu-corpo, com o intuito de interrogar sobre a possibilidade de interpretá-la a partir da fenomenologia. O eu-corpo não resulta de uma concepção fisiológica ou objetivista. Trata-se de uma experiência constituída através da percepção e da projeção mental de uma superfície de contato. Ou seja, a perspectiva freudiana de uma ligação entre eu e corpo na noção eu-corpo não nega que a dimensão biológica seja igualmente constitutiva do corpo e não afirma, tampouco, que o corpo se reduz ao eu.

Essa tese corresponde, em muitos aspectos, ao que se chamou de corpo próprio em algumas vertentes da fenomenologia. Por isso, dedicaremos um último ponto a examinar, especialmente a partir da abordagem do corpo próprio em Maurice Merleau-Ponty e Michel Henry, quais seriam as suas consequências para a psicanálise. Pretendemos, assim, confirmar a nossa hipótese de que a experiência do corpo próprio constitui um horizonte promissor de diálogo, ainda em aberto, entre a psicanálise e a fenomenologia.

\section{A consciência "como fenômeno" e a consciência "dos filósofos"}

A psicanálise de Freud costuma ser dividida entre a proposição da primeira tópica (consciente, pré-consciente e inconsciente), formulada nos primeiros textos da psicanálise, especialmente na Interpretação dos Sonhos (1900) e nos 
Três ensaios sobre a sexualidade (1905), e a proposição da segunda tópica (eu, isso e supereu), formulada em O eu e o isso (1923). É na segunda tópica, especialmente em O eu e o isso, que Freud esboça a noção de eu-corpo (Körper-Ich), ou seja, a noção que pretendemos investigar e explorar neste artigo.

O eu e o isso é um texto curto, mas notável, sobretudo por seu poder de síntese e a sua capacidade de incorporar diversos aspectos teóricos da psicanálise, desde 1895 até 1923, ano de sua publicação. Não faremos uma interpretação sistemática dos cinco itens que compõem o texto, uma vez que o nosso propósito é elucidar, de maneira delimitada, uma pista que se encontra no primeiro item e alguns aspectos que se apresentam no segundo item do texto.

O primeiro item de $\mathrm{O}$ eu e o isso destina-se a incorporar os elementos da primeira tópica. Ou seja, Freud não pretendia abandonar ou se desfazer dos conceitos de consciência e inconsciente, mas colocá-los em uma outra grade de intepretação. O que pensava Freud sobre a fenomenologia e a psiquiatria fenomenológica? Infelizmente, somente podemos encontrar uma pista de reposta a essa pergunta. Em uma nota de rodapé, Freud rejeita a perspectiva fenomenológica enquanto ela resulta na negação do inconsciente, mas parece não recusar a ideia da consciência como fenômeno. É como se as temáticas fenomenológicas da consciência e da estrutura perceptiva e atencional fossem campos de investigação paralelos à psicanálise, na medida em que a esta importa a investigação do inconsciente. Este ponto e suas consequências para uma aproximação entre psicanálise e fenomenologia é o que vamos doravante abordar.

Um fato pouco sinalizado pelos psicanalistas e nos estudos de psicanálise é que Freud foi aluno de Franz Brentano na Universidade de Viena. Não seria exagerado afirmar que a relação entre Freud e Brentano foi praticamente negligenciada, seja pelos estudiosos da corrente fenomenológica, em filosofia e psicologia, seja pelos estudiosos da psicanálise. No Brasil, dois artigos publicados por Thiago Cataldo-Maria e Monah Winograd lançaram luzes sobre a estreiteza da relação histórica entre Freud e Brentano, além da influência do conceito de intencionalidade e 
de representação no pensamento de Freud 4 . Em 1874, ano da publicação de Psicologia desde o ponto de vista empírico, Freud opta pelo curso de Brentano quando o curso de filosofia já não era mais obrigatório para estudantes de medicina e permanece seu aluno por três anos.

Não nos parece plausível que Freud tenha deixado de acompanhar as evoluções da teoria brentaniana em Viena e seus principais desdobramentos: a fenomenologia de Edmund Husserl e a fenomenologia experimental de Carl Stumpf - da qual descende a Psicologia da Gestalt. Lembremos que o tema central da fenomenologia é a percepção e que o fenomenólogo, assim como psicólogo gestaltista estão interessados, de maneira geral, em descrever a consciência perceptiva, suas modulações, o seu processo atencional, a relação figura-fundo e outros aspectos constitutivos da experiência perceptiva.

Para Freud, a consciência ou o ato mental de "estar consciente" caracteriza-se, por excelência, pela percepção. "Estar consciente é, primeiramente, uma expressão puramente descritiva, a qual invoca a percepção imediata e segura"5. A partir daí, dois processos distintos são apresentados, seja através do conteúdo latente - pré-consciente - capaz de tornar-se consciente, e a formação de conteúdos inconscientes pelo recalcamento, não mais acessiveis à consciência. $O$ primeiro processo relaciona-se à memória e foi amplamente estudado pelas escolas da fenomenologia transcendental e da fenomenologia experimental. Não haveria, aqui, nenhuma incompatibilidade entre a psicanálise e a psicologia brentaniana: ademais, "estar consciente" como expressão descritiva e a sua invocação da "percepção imediata e segura" correspondem diretamente à teoria de Brentano. O problema ou a diferença entre as vertentes reside na afirmação do inconsciente. Já em Brentano se mostrava uma resistência ao conceito de inconsciente e, de

\footnotetext{
4 Cf. CATALDO-MARIA, Thiago Marcellus de S.; WINOGRAD, Monah. Freud e Brentano: mais que um flerte filosófico. Psico, v. 44, n. 1, p. 34-44, 2013; CATALDO-MARIA, Thiago Marcellus de S.; WINOGRAD, Monah. Freud, Brentano e a Concomitância dependente. Psicologia: Teoria e Pesquisa, v. 33, n. 1, 2017, p. 1-9.

5 FREUD, Sigmund. Das Ich und das Es, op. cit., p. 283. Tradução nossa.
} 
certo modo, vamos reencontrá-la, com diferentes nuances, em diversos autores da fenomenologia. Vejamos o caso de Brentano e mais dois exemplos.

$\mathrm{Na}$ segunda parte da Psicologia do ponto de vista empírico, Brentano sustenta a tese de que "todo ato psíquico é acompanhado de uma consciência correlativa"6. Há nesta parte um capítulo que versa sobre a consciência interior (Vom innere Bewusstsein), tema que foi objeto de inúmeras controvérsias nos primórdios da psicologia experimental do séc. XIX. Brentano toma uma clara posição contra todos os pensadores que defenderam algum tipo de representação inconsciente, como Herbart, Fechner, Ulrici e, especialmente, a Filosofia do Inconsciente, de Karl Robert Eduard von Hartmann7 (lançado em 1869, com grande repercussão por tentar conciliar a filosofia de Kant, Hegel e Schopenhauer). O grande problema da "representação inconsciente", para Brentano, é que não podemos tomar contra ela a experiência e tampouco invocar como testemunho (Zeugnis) a experiência. Brentano reconhece que Von Hartmann, o defensor de uma "consciência inconsciente" (unbewußte Bewußtsein), deu-se ele mesmo conta disso e por essa razão teria sustentado que o inconsciente somente pode ser deduzido indiretamente dos fatos da experiência. Esta é a tese que Brentano procura arguir ao longo do mesmo capítulo. Brentano afirma que todo ato psíquico é consciente e nega categoricamente a existência de representações inconscientes. Contase que um filósofo teria dito a Brentano certa vez "Penso que temos que colocar o problema das questões não conscientes como tema da psicologia: temos que tratar do inconsciente na ciência da psicologia"; ao que teria respondido Brentano: "Não, a universidade só trata da consciência"8.

\footnotetext{
6 BRENTANO, Franz. Psychologie vom Empirischen Standpunkte. Leipzig: Dunker \& Humblot, 1874, p. 181. Tradução nossa.

7 Ibidem, p. 133-135.

8 Cf. STEIN, Ernildo. Anamnese - A filosofia e o retorno do reprimido. Porto Alegre: Edipucrs, 1997, p. 42. Embora no texto de Ernildo Stein não esteja claro quem poderia ser este filósofo, entendemos, pela situação e pelo contexto narrado, que se tratava de Theodor Lipps. Sobre a presença e a importância deste pensador nos escritos de Freud, ver: LOPARIC, Zeljko. Theodor Lipps: uma fonte esquecida do paradigma freudiano. Natureza humana, v. 3, n. 2, p. 315-331, 2001.
} 
O segundo exemplo que gostaríamos de apresentar diz respeito ao principal continuador de Brentano. A fenomenologia de Edmund Husserl divergiu do psicologismo e da metodologia do seu mestre, mas aparentemente guardou deste a intenção de afastar do estudo teórico e científico as representações inconscientes. Para Husserl, a correlação é um "a priori" universal da consciência intencional. Vejamos este trecho da Crise das ciências europeias e a Fenomenologia Transcendental, publicada originalmente em 1936 e posteriormente retomada nas Husserliana: "O mundo sempre permanece, então, consciente na consciência desperta, em validade como horizonte universal." $\mathrm{A}$ percepção refere-se somente ao presente. Através da análise intencional da recordação e da continuidade através das retenções e protensões, seria possível alcançar os diversos modos de presentificação dos objetos, com as intencionalidades "abertas" ou "implícitas". Em um comentário anexo a esse parágrafo da Crise, Eugen Fink faz uma dura crítica à noção de inconsciente: "Os problemas que se anunciam sob o título de 'inconsciente' só podem ser compreendidos e expostos metodicamente de modo suficiente no seu caráter próprio de problemas segundo a analítica precedente do 'ser consciente'”'10. E, em seguida: “Acredita-se sempre conhecer já o que é o 'consciente', a consciência, e dispensa-se da tarefa de tematizar previamente o conceito, perante o qual toda ciência do inconsciente tem sempre de delimitar o seu tema, exatamente o da consciência"11. Fink queria assinalar que somente após uma analítica explícita da consciência poderia ser levantado o problema do inconsciente.

No entanto, é importante esclarecer que Husserl não tinha resistência para tratar dos problemas "inconscientes". A possível abordagem assinalada por Fink de compreender os problemas do inconsciente através da fenomenologia

9 HUSSERL, Edmund. Die Krisis der europäischen Wissenschaften und die Transzendentale Phänomenologie. Husserliana VI. 2. ed. The Hague: Martinus Nijhoff, 1962, p. 163. Tradução nossa.

10 FINK, Eugen. Finks Beilage zum Problem des 'Unbewußtes'. HUSSERL, Edmund. Die Krisis der europäischen Wissenschaften und die Transzendentale Phänomenologie, op. cit., p. 474. Tradução nossa.

11 Ibidem. Tradução nossa. 
chegou a ser iniciada por Husserl. É o que comprova o recente volume XLII das Husserliana, no qual foram publicados manuscritos sobre os Problemas Limítrofes (Grenzprobleme) da fenomenologia (o nascimento, o sono e a morte), bem como sobre o inconsciente e uma fenomenologia dos instintos (Phänomenologie der Instikte) e das pulsões instintivas (instinktive Triebe) ${ }^{12}$. Lamentavelmente, a metodologia fenomenológica empregada por Husserl, mesmo nesse manuscrito, não leva em consideração a tradição psicanalítica.

Ainda um terceiro exemplo merece aqui a nossa atenção. O pensador francês Jean-Paul Sartre faz o seu primeiro contato com a fenomenologia em 1934. Desde então e até o final de sua obra, Sartre criticará o conceito de inconsciente da psicanálise freudiana. Entre os diversos argumentos utilizados por Sartre, ele sustenta em O Ser e o Nada que não seria possível conceber uma censura que não fosse consciência não tética de censura, ou seja, consciência (de) censura, ou consciência implícita de censura. Em outros termos, se a censura discerne quais são as pulsões recalcáveis, como ela o faria, senão sob a forma de uma consciência (de) censura? ${ }^{13}$ Para Sartre, as operações que na psicanálise estariam sob a égide do inconsciente devem ser descritas no âmbito da própria consciência não tética e irrefletida, dimensão existencial e não objetal da consciência.

No entanto, convém assinalar que Sartre manteve-se continuamente em diálogo com a psicanálise, embora tenha operado com uma conceitualidade própria e crítica, derivada da sua psicanálise existencial e do método progressivo-regressivo. Ao final de sua obra, no Idiota da Família, Sartre emprega a noção de "vivido" para descrever o caso Flaubert, evitando o que ele chama de "determinismo psicanalítico". "Com a ajuda desta noção, eu tentei ultrapassar a tradicional ambiguidade psicanalítica do fato psíqui-

\footnotetext{
12 HUSSERL, Edmund. Grenzprobleme der Phänomenologie. Analysen des Unbewußtseins und der Instinkte. Metaphysik. Späte Ethik. (1908-1937). Husserliana XLII. Nova lorque: Springer, 2014. Tradução nossa.

13 SARTRE, Jean-Paul. L'Être et le Néant - Essai d'ontologie phénoménologique. Paris: Gallimard, 1943, p. 87.
} 
co - ao mesmo tempo teleológico e mecânico". ${ }^{44}$ Dessa forma, através do "vivido", Sartre pretende descrever como todo fato psíquico implica uma intencionalidade, embora alguns desses fatos só possam efetivamente existir se forem objetos de uma compreensão (no vivido), sem serem nomeados ou conhecidos. Em um texto deste mesmo período final de sua obra, ele chega a se dizer um "companheiro de estrada crítico" da psicanálise ${ }^{15}$.

Com esses três exemplos, é possível ilustrar o modo como, na tradição fenomenológica, permaneceu, ainda que com traços diferentes e por diferentes razões, uma espécie de suspeita acerca da afirmação do inconsciente. Freud conheceu e foi aluno de Brentano e certamente teve contato com a resistência oferecida por este a tratar das representações inconscientes - já defendidas por autores do século XIX. Depois da criação da psicanálise em 1895, foram necessários anos de esforço e divulgação para que Freud alcançasse um reconhecimento institucional.

Voltemos ao nosso ponto de estudo. Se, de um lado, Brentano e alguns fenomenólogos tiveram restrições com o emprego da noção de "inconsciente", Freud, ao contrário, não possui restrição alguma com a concepção fenomenológica da consciência. O seu único problema, e podemos compreendê-lo, está no uso da descrição da consciência para recusar o inconsciente. É isso o que podemos concluir a partir da leitura de uma rara e surpreendente nota de $O$ eu e o isso sobre o tema da consciência perceptiva na acepção fenomenológica. Freud evidencia exatamente o que acabamos de afirmar.

Alguns pesquisadores que não se furtam a reconhecer os fatos psicanalíticos, mas não querem admitir o inconsciente, buscam uma saída no fato incontroverso de que também a consciência - enquanto fenômeno - apresenta muitas gradações de intensidade ou nitidez ${ }^{16}$.

\footnotetext{
14 SARTRE, Jean-Paul. "Sartre par Sartre". Situations, IX. Paris: Gallimard, 1972, p. 112. Tradução nossa.

15 SARTRE, Jean-Paul. "L'homme au magnétophone”. Situations, IX. Paris: Gallimard, 1972, p. 329. Tradução nossa.

16 FREUD, Sigmund. Das Ich und das Es, op. cit., p. 285. Tradução nossa.
} 
Quais seriam estes pesquisadores aos quais Freud se refere? Não há nenhuma referência direta nesta passagem, mas tudo indica que Freud se refere à tradição fenomenológica em sentido amplo, pois fala da consciência "enquanto fenômeno" (als Phänomen). Para Freud, as gradações de intensidade ou nitidez da consciência são fato incontroverso (unbestrittene Tatsache), ou seja, a questão se coloca em outro plano.

Freud refere-se ao fato de que os filósofos e psicólogos (provavelmente do movimento fenomenológico) descrevem os vários graus de intensidade da consciência e confundem isso com o inconsciente. Ao transportar o dinamismo inconsciente ao campo da consciência, tais pesquisadores equiparam o não notado (Unbemerkte) ao inconsciente, incorrendo no mesmo preconceito (Vorurteil) que vê como estabelecida a identidade entre o psíquico e o consciente ${ }^{17}$. Ao que o próprio texto parece indicar, Freud não tem nenhuma ressalva em relação à concepção fenomenológica da consciência, senão à tentativa de absorver o inconsciente nas descrições das camadas menos intensas ou implícitas da consciência.

Faremos ainda uma breve digressão que confirma nossa análise. Em um de seus últimos textos, O esquema da psicanálise, escrito em 1938, com o propósito de reunir os princípios da psicanálise e expô-los de forma didática, Freud uma vez mais retorna ao conceito de consciência "dos filósofos". Ao tratar das diferenças entre inconsciente, pré-consciente e consciente, Freud afirma:

Não faz falta que caracterizemos [o consciente]; é o mesmo que a consciência dos filósofos e da opinião popular [das Bewusstsein der Philosophen und Volksmeinung]. Todo o outro psíquico [Alles andere Psychische] é para nós o inconsciente ${ }^{18}$.

\footnotetext{
17 Ibidem, p. 286.

18 FREUD, Sigmund. Abriss der Psychoanalyse. Vol. XVII - Gesammelte Werke. Londres: Imago, 1941, p. 81. Tradução nossa.
} 
É evidente que esta passagem, lida em seu contexto, tem a força retórica de sublinhar que o inconsciente é o campo de estudo da psicanálise. Por outro lado, Freud refere-se aos "filósofos" de forma genérica, de modo praticamente equiparado à opinião popular ou, se quisermos, ao senso comum. Com isso, fica marcado que o estudo da consciência não era uma questão imprescindível para Freud, uma vez que ele parece aderir ao senso comum e ao que os "filósofos" definem como sendo a consciência, sem explicitar ou sequer mencionar o fato de que o problema da consciência está longe de ser um ponto pacificado no debate filosófico.

Ao que tudo indica, Freud estava mais preocupado em garantir o inconsciente como campo de estudo para a psicanálise, parecendo desprezar o debate histórico em torno da definição filosófica sobre o que é a consciência. Não obstante, no momento em que Freud aceita "a consciência como fenômeno" ou "consciência dos filósofos", abre-se apesar de todas as resistências recíprocas entre fenomenólogos e psicanalistas, uma perspectiva de aproximação entre a psicanálise e a fenomenologia.

\section{$2 \mathrm{O}$ isso e seu investimento pulsional sobre o eu}

A noção de eu-corpo, que a nosso juízo permitirá estabelecer uma abordagem fenomenológica da psicanálise freudiana, necessita, para ser compreendida, de um entendimento prévio sobre o que significa o isso, introduzido por Freud no segundo item de $O$ eu e o isso. A compreensão do eu-corpo se faz sobre a base conceitual do eu como instância psíquica que surge ela mesma de uma diferenciação do isso.

É sabido que um dos grandes motivos da investigação freudiana, e consequente formulação da psicanálise, deveu-se à tentativa de interpretar os casos histéricos. Já de posse de várias hipóteses propriamente psicanalíticas, Freud apresenta o caso Dora em Fragmentos da análise de um caso de histeria (1905). Nessa obra, podemos perceber as investidas de Freud para tratar a relação do corpo com a psique compreendendo os sintomas corpóreos como uma maneira de ocultar desejos inconscientes. O corpo não chega a ser visto 
nessa obra como uma via que afeta o psíquico, mas doenças prévias podem preparar para a manifestação das tensões psíquicas e, desse modo, Freud percebe a indissociabilidade entre sofrimento corpóreo e psíquico. Freud chama atenção para o aspecto receptivo do corpo em relação às demandas psíquicas, talvez uma de suas contribuições mais importantes para a psicologia somática, afirmando a necessidade do corpo ser em algum grau somaticamente condescendente (ein gewisses somatisches Entgegenkommen) ${ }^{19}$.

Contudo, Freud não retorna à essa tese, a não ser en passant, deixando-a livre para formulações de outros autores, como Georg Groddeck. Segundo Le Vaguerèse, ${ }^{20}$ Groddeck tomou conhecimento dos trabalhos de Freud em 1912, inclusive tecendo algumas considerações críticas em sua obra O homem saudável e doente (Nasamecu) de 1913, porém somente em 1917 é que faz efetivo contato com o fundador da psicanálise. Assim como Groddeck é influenciado pela psicanálise, Freud foi afetado pelas formulações de Groddeck como atestam as dezenas de cartas que trocaram entre o período de 1917 e 1923, sobretudo na concepção de isso (das Es) como o próprio Freud afirmou em nota na obra $\mathrm{O}$ eu e o isso. Embora ambos estivessem em franca divergência em pontos centrais, houve um intenso intercâmbio intelectual entre eles ${ }^{21}$. Importante para esse trabalho é notar como a noção de isso de Groddeck enriquece a noção de corpo em Freud.

Sob os estímulos de Freud, e um convite para publicar na revista psicanalítica, Groddeck publicou em 1921 um romance psicanalítico que antecipava

\footnotetext{
19 FREUD, Sigmund. Bruchstück einer Hysterie-Analyse. Vol. VIII - Gesammelte Schriften. Krankengeschiscten. Leipzig; Wien; Zürich: Internationaler Psychoanalytischer, 1924, p. 40. Tradução nossa.

20 LE VAGUERĖSE, Laurent. Introdução à obra de Groddeck. In: NASIO, Juan-David. Introdução às obras de Freud, Ferenczi, Groddeck, Klein, Winnicott, Dolto, Lacan. Rio de Janeiro: Zahar, 1995. p. 114-115.

${ }^{21}$ Pelo escopo do presente trabalho, não é possível explorar todas as influências que Freud recebe e as que rejeita de Groddeck; mas, para quem esteja interessado, remetemos a dois trabalhos que destacam várias dessas influências (ambos em nossa bibliografia): o capítulo de Laurent le Vaguerèse no livro de Juan David Nasio e a tese de Maria Consuelo Silva.
} 
as ideias que ele escreveria para o Livro do Isso $\mathrm{s}^{22} \mathrm{em} 1923$. Porém, Groddeck molda a noção de isso muito antes dessa publicação da qual Freud toma o termo para os seus próprios propósitos. É verdade que Freud conjectura em $\mathrm{O}$ eu e o isso que o isso de Groddeck tenha a influência de Nietzsche. Entretanto, Martynkewics, o biógrafo de Groddeck, aponta outra origem: Wilhelm Bölsche escreveu, em 1904, O ressurgimento da religião através da arte em que afirma o isso como uma força condutora, criativa e que se poderia chamar de "Deus"23. Groddeck toma esse motivo religioso de Bölsche como referência ao moldar o seu conceito de isso. Martynkewicz ${ }^{24}$ ainda aponta que mesmo Bölsche retirou o isso de Goethe, porém é a partir dele que Groddeck chega ao isso com esse fundo romântico do "Deus-natureza" de Goethe.

Groddeck possui uma concepção da relação do ser humano com a natureza que é sustentada por essa visão mística do "Deus-natureza" (Gottnatur) de Goethe. Tal concepção aparece explicitamente em sua obra de 1913, O homem saudável e doente, em que anuncia que os aspectos saudáveis e doentes do ser humano não são verdadeiramente opostos, mas expressões que vêm do interior, que vêm do isso ${ }^{25}$. O isso assume uma dimensão fundadora do humano, como força vital, tanto quanto da natureza. Não há mais para Groddeck diferença fundamental entre natureza e humano, sendo que se relacionam como expressões de algo anterior que lhes sustenta: $\mathrm{o}$ isso. É com essa perspectiva que afirma, em o Livro do Isso, ${ }^{26}$ que o organismo não pode ser distinguido da personalidade de cada um. Em diversas passagens dessa obra, Groddeck fornecerá exemplos ilustrativos de como entende a relação do organismo com a

\footnotetext{
22 GRODDECK, Georg. Das Buch vom Es. Leipzig; Wien; Zürich: Internationaler Psychoanalytischer, 1923.

23 MARTYNKEWICZ, Wolfgang. Georg Groddeck: Eine Biographie. Frankfurt am Main: Fisher, 2015, p.191. Tradução nossa.

24 Ibidem, p.192.

25 GRODDECK, Georg. Der gesunde und kranke Mensch (Nasamecu). Leipzig: Hirzel, 1913, p.10-13.

${ }_{26}$ GRODDECK, Georg. Das Buch vom Es. Leipzig; Wien; Zürich: Internationaler Psychoanalytischer, 1923, p.14.
} 
subjetividade; contudo, essencialmente, podemos perceber que para ele o corpo não está estreitamente ligado à subjetividade, mas é, antes, uma forma dessa mesma subjetividade. O ser humano é determinado pelo isso, ou melhor, somos vividos pelo isso, e o eu é uma ilusão em Groddeck.

Fica muito claro que Freud não aceita essa tendência ao misticismo de Groddeck já desde o seu primeiro contato com ele em 1917, como atesta uma carta endereçada à Lou Andreas-Salomé, ${ }^{27}$ em que recomenda a leitura do autor com ressalvas por "sua tendência ao exagero e à simplificação, e um certo elemento de misticismo"28. Embora Freud tenha tomado o termo isso (das Es) no encontro com Groddeck e formulado a segunda tópica também perpassada por esse intercâmbio, o que Freud aceita de Groddeck é muito pouco do que esse desenvolveu. Contudo, esse pouco, deixa marcas importantes para o conceito que Freud levará adiante a partir dessa época. Freud aceita de Groddeck essa força criadora, pulsional, do isso e o coloca em íntima relação com o sensório. O eu não é para Freud uma ilusão, certamente, mas divide espaço com o isso na nova organização do aparelho psíquico da segunda tópica.

Freud, em concordância com Groddeck, situa o isso como algo que é em nós “impessoal” e comporta-se como a outra parte da psique (das andere Psychische), i.e., inconsciente ${ }^{29}$. O eu passa a funcionar como uma organização do aparelho psíquico responsável principalmente pela inibição dos processos primários, entidade que parte do sistema perceptivo. Pode-se perceber que Freud incorpora certa dimensão "abarcadora” do isso como em Groddeck, sobretudo na obra $\mathrm{O}$ eu e o isso, quando reconhece no eu somente uma su-

\footnotetext{
27 FREUD, Sigmund; SALOMÉ, Lou Andreas. Correspondência Completa. Dora Flacksman. Rio de Janeiro: Imago, 1975, p. 88-89.

${ }_{28}$ Maria Consuelo comenta essa carta mostrando que, pela resposta de Lou Andreas-Salomé a Freud, ela já conhecia a obra de Groddeck, sendo talvez a única psicanalista a conhecê-lo antes de seu trabalho na revista coordenada por Freud. A autora também traz a menção de uma carta de 1922 de Freud, endereçada a Ferenczi, em que ele faz comentários nada elogiosos ao trabalho de Groddeck. Ver SILVA, Maria Consuelo da Costa Oliveira. O legado de Georg Groddeck: genuinidade e originalidade. Dissertação de mestrado em psicossomática e psicologia hospitalar. São Paulo: PUCSP, 2009, p.112.
}

29 FREUD, Sigmund. Das Ich und das Es, op. cit., p. 292. Tradução nossa. 
perfície de um isso psíquico, e que o eu não é nitidamente separado do isso, mas com ele flui ${ }^{30}$. Com essa constatação que Freud aceita de Groddeck, o eu não pode mais ser pensado como uma instância plenamente consciente. A consciência não corresponde à instância concebida como eu, embora, para Freud, o eu se caracterize principalmente pela função senso-perceptiva.

O eu agora compreendido como superfície psíquica, derivado dos estímulos sensórios, passa a ter uma importância funcional de regulação e mediação entre pulsões e estímulos. Freud reconhece essa fronteira do corpo próprio - sobretudo a superfície (der eigene Körper und vor allem die Oberfläche desselben), ${ }^{31}$ salienta - funcionando como mediador simultaneamente das percepções internas e externas. $\mathrm{O}$ isso, com o seu aspecto groddeckiano de força criativa e ctônica, é assimilado em Freud como esse outro psíquico em que vigora o caráter irrestrito do princípio do prazer, formado pelas pulsões. $\mathrm{O}$ isso funciona no esquema de Freud como um reservatório de energia com o qual o eu "negocia" benefícios introjetando as suas catexias. As representações em circulação no inconsciente não estão associadas às palavras e possuem as mesmas características identificadas nos sonhos em $A$ interpretação dos sonhos (1900), quais sejam, as características de condensação e deslocamento

Que o eu não esteja mais identificado com a consciência em Freud não implica que o eu não esteja ligado a ela. Tal ligação com a consciência, e ao sistema perceptivo como já dissemos, implica que o eu está apto a agir sobre o mundo externo também porque o percebe. Embora aqui não seja o lugar para explorar toda a gênese do eu enquanto delta e foz das sensações corporais e pulsões do isso, cabe lembrar que a conformação do eu está ligada de modo originário à relação do cuidador primário com o lactente - o que remete ao narcisismo primário -, além de seu entorno imediato. Nesse processo, o eu é investido libidinalmente, constituindo fonte de onde pode passar a investir objetos satisfazendo a pulsão. $O$ eu, então,

30 Ibidem, "Das Ich ist vom Es nicht scharf getrennt, es fliesst nach unten hin mit ihm zusammen".

${ }^{31}$ FREUD, Sigmund. Das Ich und das Es, op. cit., p. 294. 
claramente responde às demandas que vêm do isso, organizando essas forças para responder também ao modo como o mundo se apresenta a ele.

Freud parece fazer uma síntese de suas pesquisas anteriores em $\mathrm{O}$ eu e o isso, porém incorporando vários aspectos dos autores que confronta, além da nova formulação metapsicológica da estrutura do psíquico. Embora neste caso recuse formulações oriundas dos filósofos, ${ }^{32}$ não consegue ignorar questões que ampliam a sua compreensão da psique humana. $\mathrm{E}$ é isso que Groddeck oferece à Freud, a compreensão de forças incontroláveis no interior de cada sujeito que não são de todo distinguíveis das forças ditas controláveis; não se reduzem ao orgânico, mas com ele têm íntima ligação; não são puramente identificadas à psique e nem somente ao corpo. Fica claro esse débito com Groddeck em como concebe o isso e as implicações para a noção de eu; agora já não tão independente das demais funções, mas indissociável do corpo e da força que o sustenta internamente, i.e., o isso. Porém, também deve ficar claro, o cuidado de Freud em não importar um misticismo e certo apagamento das características próprias do eu e do corpo próprio fazendo-os meras expressões do isso.

$\mathrm{O}$ eu, a partir de $\mathrm{O}$ eu e o isso, passa a ser compreendido como um eu-corpo (Körper-ich), por indissociável da dimensão perceptiva. Não se trata pura e simplesmente do corpo (fisiológico) e não se trata pura e simplesmente de uma identificação com a dimensão pulsional (a pulsão está entre o psíquico e o somático). "O eu é sobretudo corporal, não é apenas uma entidade superficial, mas ele mesmo a projeção de uma superfície". O eu consciente é sobretudo um eu-corpo. O eu-corpo é o que Freud entende por eu consciente, pela consciência de si como eu. A consciência faz-se consciente de si como eu enquanto eu-corpo. Tais formulações continuarão ressoando na obra posterior de Freud, entretanto com menos brilho e muitas vezes em franca tensão com formulações aparentemente organicistas do aparelho psíquico. Contudo, essa perspectiva

32 ASSOUN, Paul-Laurent. Freud e Nietzsche: semelhanças e dessemelhanças. São Paulo: Brasiliense, 1989, p. 11. 
em Freud abre espaço para avançar um tratamento fenomenológico da psicanálise, algo que muitas vezes se pensou inviável pela própria postura de desconfiança que Freud sustentou contra os filósofos.

\section{Eu-corpo como percepção e projeção da superfície do corpo próprio}

Passaremos à terceira etapa de nossa abordagem, seguindo mais algumas pistas dadas em $\mathrm{O}$ eu e o isso. Freud introduz a noção de isso e o diferencia do eu, como vimos no ponto anterior. Esse gesto não nega a construção da primeira tópica (consciente, pré-consciente e inconsciente), mas recoloca a perspectiva do funcionamento dinâmico do aparelho psíquico em termos topológicos.

Graças a essa recomposição, Freud amplia o conceito de inconsciente, uma vez que o isso se define por uma dimensão inconsciente pulsional não recalcada. A correta compreensão deste aspecto permite dissipar possíveis mal-entendidos que nascem de uma visão excessivamente esquematizadora da segunda tópica. É preciso ter o cuidado de não simplificar a subdivisão das três instâncias psíquicas em Freud, identificando o eu com a consciência e o isso com o inconsciente. Nesse sentido, o inconsciente recalcado, tal como havia sido descrito na primeira tópica, não é sinônimo de isso. "O inconsciente não coincide com o recalcado". 33 Por outro lado, o eu não é sinônimo de consciência de si para Freud. "O eu é também, como aprendemos, inconsciente"34.

Nessa reconstrução teórica, a relação entre o corpo e o sistema perceptivo ganha uma abordagem totalmente nova, que leva Freud a formular a noção Körper-ich, o eu-corpo. É preciso reconhecer que Freud não desenvolve essa noção e muito menos oferece uma teoria do corpo em sua obra. Neste ponto, concordamos com a análise de Christophe Dejours, segundo a qual

\footnotetext{
33 FREUD, Sigmund. Das Ich und das Es, op. cit, p. 287. Tradução nossa.

34 Ibidem, p. 292. Tradução nossa.
} 
uma teoria do corpo "não existe na metapsicologia freudiana"35. Além disso, afirma o psicanalista francês: "Ademais, porque Freud considera o corpo exclusivamente como um corpo objetivo"36. Vejamos por quê. Dejours escolhe um trecho de Pulsões e Destinos da Pulsão para corroborar a sua tese de que Freud chega a negar que a psicanálise tenha mesmo algo a dizer sobre o corpo, cujo estudo pertenceria à biologia. Com efeito, neste famoso artigo, ao tratar da relação entre o somático e o pulsional, Freud desloca o estudo das fontes somáticas das pulsões para outro campo que não o da psicologia:

Por fonte da pulsão entende-se aquele processo somático, interior a um órgão ou a uma parte do corpo, cujo estímulo é representado na vida psíquica pela pulsão. Não se sabe se esse processo é por regra geral de natureza química ou também pode corresponder ao desprendimento de outras forças, mecânicas por exemplo. 0 estudo das fontes pulsionais já não compete à psicologia: ainda que para a pulsão o absolutamente decisivo é sua origem na fonte somática, não nos é conhecida na vida da alma de outro modo senão por suas metas ${ }^{37}$.

Chama-nos atenção, no entanto, que Dejours não tenha mencionado nesse mesmo artigo a concepção de eu-corpo (Körper-ich) proposta por Freud em $\mathrm{O}$ eu e o isso. Em outros termos, ainda que Freud não tenha oferecido uma teoria do corpo e tenha deslocado o estudo das origens das pulsões ao campo biológico (e nisso concordamos com Dejours), é preciso destacar que a concepção do eu como uma parte modificada do

35 DEJOURS, Christophe. "O corpo entre psicanálise e fenomenologia da vida". ANTÚNEZ, Andrés Eduardo Aguirre; MARTINS, Florinda; FERREIRA, Maristela Vendramel. Fenomenologia da vida em Michel Henry - Interlocução entre filosofia e psicologia. Trad.: Isabelle Gayon. São Paulo: Escuta, 2014, p. 211.

36 Ibidem, p. 211.

37 FREUD, Sigmund. Triebe und Triebschicksale. Vol. III - Studienausgabe. Frankfurt am Main: Fischer, 1975, p. 86-87. Tradução nossa. 
isso levou Freud a adotar uma nova concepção de corpo, cujo modelo abre diversas zonas de intersecção com a fenomenologia.

O eu-corpo não é pura e simplesmente o corpo fisiológico (biológico) e, neste sentido, não se identifica com a fonte somática das pulsões - embora esteja relacionado com esta dimensão. Vejamos como Freud constrói esta noção, em duas etapas: (1) o eu constitui-se através da percepção e (2) caracteriza-se como uma projeção de superfície.

O eu constitui-se através da percepção. "A percepção tem, para o eu, o papel que no isso cabe à pulsão". ${ }^{38}$ Ou seja, quando Freud se refere ao eu como a parte do isso modificada pela influência do mundo externo, é sob a mediação (Vermittlung) do sistema perceptivo que a modificação se opera. ${ }^{39}$ Sob a égide do princípio de realidade, a importância funcional do eu expressa-se através do seu controle sobre a motilidade. ${ }^{40}$ Freud utiliza aqui a famosa metáfora do cavaleiro (Reiter) que coloca freios à força superior do cavalo (Pferd). Dessa forma, o eu está relacionado por princípio com a senso-percepção e com a motilidade do corpo.

Freud aponta ainda um segundo aspecto constitutivo do eu, que diz respeito à própria superfície (Oberfläche) do corpo próprio (der eigene Körper) como local de onde podem partir as percepções externas e internas. "O corpo próprio e sobretudo a sua própria superfície é o lugar do qual podem partir simultaneamente as percepções externas e internas". ${ }^{41}$ O próprio corpo pode ser percebido ambiguamente como outro objeto, em razão dos dois tipos de sensações produzidas.

Façamos aqui uma breve pausa. Para pensar essa ambiguidade perceptiva à qual se refere Freud, podemos dar o exemplo de uma mão que toca a outra, que por sua vez toca um objeto externo. Esse exemplo foi amplamente explorado em fenomenologia. Merleau-Ponty descreveu, na

\footnotetext{
${ }^{38}$ FREUD, Sigmund. Das Ich und das Es, op. cit., p. 293. Tradução nossa

39 Ibidem, p. 293. Tradução nossa.

40 Ibidem, p. 294.

${ }^{41}$ Ibidem, p. 294. Tradução nossa.
} 
Fenomenologia da Percepção, casos de membro fantasma (onde o membro amputado é ainda sentido) e de anosognosia (de pessoas que ignoram a sua mão paralisada $)^{42}$. Mais tarde, em $O$ Visível e o Invisível, MerleauPonty examinou expressamente o exemplo de uma mão que toca a outra:

Minha mão esquerda está a ponto de tocar minha mão direita que toca as coisas, mas eu não chego jamais à coincidência, ela se eclipsa no momento de se produzir, e é sempre de duas coisas uma: ou verdadeiramente minha mão direita passa à posição de tocada, mas então a sua tomada sobre o mundo se interrompe - ou bem ela a conserva, mas é porque eu não a toco verdadeiramente, ela, eu só palpo com a mão esquerda o seu invólucro exterior ${ }^{43}$.

A questão gerou um interessante debate em fenomenologia. Na última fase de seu pensamento, Merleau-Ponty tinha a pretensão de estender ao próprio mundo a relação entre o que sente e o sentido, o que vê e o visível, tocante e tocado. Por sua vez, Michel Henry faz uma leitura crítica desta tese, que ele qualifica de "absolutização do sensível", no sentido de que a dupla possibilidade inerente ao corpo transcendental de se fazer mundo (tocante e tocado) teria sido reportada por Merleau-Ponty ao próprio mundo sensível ${ }^{44}$.

Voltemos ao Eu e o isso. Não obstante a importância da superfície corpórea como demarcador daquilo que é o corpo próprio no contato com o mundo externo, Freud toma o cuidado de afirmar que o eu não é apenas a superfície, mas a projeção de uma superfície. "O eu é sobretudo corporal, ele não é somente um ente superficial, mas ele mesmo a projeção de uma superfície"45. O que

42 Cf. MERLEAU-PONTY, Maurice. Phénoménologie de la Perception. CEuvres. Paris: Gallimard Quarto, 2010, p. 754.

43 MERLEAU-PONTY, Maurice. Le visible et l'invisible. Euvres. Paris: Gallimard Quarto, 2010, p. 1772. Tradução nossa.

44 HENRY, Michel. Incarnation - Une philosophie de la chair. Paris: Seuil, 2000, p. 163-166.

45 FREUD, Sigmund. Das Ich und das Es, op. cit., p. 294. Tradução nossa. 
Freud pretende dizer com isso? Que a superfície do corpo não está por assim dizer "pronta", senão que ela resulta de um processo mental de projeção do eu. É nesse segundo sentido, especialmente, que o eu é um eu-corpo.

Entre os autores que se detiveram nesta questão, destacamos Didier Anzieu, que no livro Eu-pele reconhece em Freud um dos precursores de sua própria teoria, uma vez que, para Freud, "o envoltório (enveloppe) psíquico deriva por apoio (étayage) do envoltório corporal"46. Apesar de ter percebido um aspecto pouco notado por outros teóricos da psicanálise e ter construído a partir daí as suas próprias e inovadoras contribuições para a psicanálise, infelizmente Anzieu não ofereceu neste livro uma aproximação da psicanálise com a fenomenologia ${ }^{47}$.

Quando notamos em Freud que o eu se caracteriza através da senso-percepção e da motricidade, bem como a partir de um processo mental de projeção sobre a superfície do corpo, é inevitável que nos aproximemos da escola da fenomenologia. O eu não é uma instância "abstrata", uma "substância" ou uma "coisa" para Freud: o eu é uma instância psíquica resultante de um processo contínuo de contato, da mediação do aparelho psíquico com o mundo externo através das percepções externas e internas, capaz de atribuir uma identidade a si, na forma de uma consciência corpórea de si. Não há constituição do eu sem a percepção do corpo próprio. Uma tese semelhante encontramos na fenomenologia do corpo próprio em MerleauPonty e Michel Henry, com diferentes consequências para a psicanálise.

\footnotetext{
46 ANZIEU, Didier. Le Moi-peau. 2. ed. Paris: Dunod, 1995, p. 106. Tradução nossa.

47 Recentemente, na Dissertação de Mestrado Do eu-pele ao corpo próprio: corporeidade e subjetividade em Anzieu e Merleau-Ponty (2017), Fernanda Brockmann Vanassi procurou aproximar a perspectiva de Anzieu da fenomenologia merleau-pontiana, apresentando diversos pontos de contato entre ambas, como a carne, os envelopes, o espaço corporal e os espaços psíquicos. Não obstante os méritos dessa pesquisa, a falta de uma contraposição das noções de inconsciente em Merleau-Ponty e na psicanálise, por decisão metodológica de sua autora (2017, p. 93), resulta na aproximação dos autores sem a percepção de que a aceitação de uma fenomenologia do corpo exigiria uma reformulação da perspectiva psicanalítica do eu-pele em suas relações com o inconsciente.
} 


\section{0 eu-corpo e a fenomenologia do corpo próprio}

A tese central de Merleau-Ponty é que o corpo próprio não se reduz à objetividade ou a um objeto físico, pois ele se constitui e se realiza como corpo através de uma síntese das dimensões perceptiva e motora. Enquanto a tradição cartesiana e kantiana faz das determinações espaciais a essência do objeto e esclarecem a percepção do objeto através do espaço, "a experiência do corpo próprio nos ensina a enraizar o espaço na existência"48.

Na primeira parte da Fenomenologia da Percepção, voltada para a fenomenologia do corpo, Merleau-Ponty dedica um dos itens de análise ao corpo como ser sexuado e, nesse sentido, encontra a psicanálise de Freud. MerleauPonty entende que a tese psicanalítica segundo a qual "todo ato humano possui um sentido", procurando em toda parte compreender o acontecimento ao invés de ligá-lo a condições mecânicas, não contradiz a fenomenologia, mas, ao contrário, ajudou a desenvolvê-la ${ }^{49}$. No entanto, o filósofo francês parece discordar da subordinação desta tese a um primado da sexualidade.

A psicanálise representa um duplo movimento de pensamento: de um lado ela insiste na infraestrutura sexual da vida, de outro ela 'enche' ['gonfle'] a noção de sexualidade ao ponto de integrar nela toda a existência. Mas justamente por esta razão, suas conclusões [...] são ambíguas. Quando se generaliza a noção de sexualidade e se faz dela uma maneira de ser no mundo físico e inter-humano, quer-se dizer que em última análise toda existência tem uma significação sexual ou bem que todo fenômeno sexual tem uma significação existencial?50

\footnotetext{
48 MERLEAU-PONTY, Maurice. Phénoménologie de la Perception, op. cit., cf. «La synthèse du corps propre», p. 832-838. Tradução nossa.

49 Ibidem, p. 843. Tradução nossa.

5o Ibidem, p. 844. Tradução nossa.
} 
Fica claro que não se trata para Merleau-Ponty de negar a importância da sexualidade, mas sim reconduzi-la à experiência existencial do corpo próprio no qual ela se enraíza. Por outro lado, assim como a existência não se reduz ao corpo ou à sexualidade, a própria sexualidade não se reduz à existência. Para Merleau-Ponty, corpo e existência pressupõem um ao outro, de maneira que o corpo é a "existência enrijecida" (figée) e a existência é uma "encarnação perpétua"51. Há, portanto, uma implicação mútua entre o corpo e a existência sem que haja qualquer tipo de anterioridade de um em relação ao outro. Da mesma forma, o fato de que a sexualidade tenha uma significação existencial ou que ela exprima uma existência não significa que o drama sexual seja tão-somente o drama existencial. "A sexualidade não é nem transcendida na vida humana nem figurada em seu centro por representações inconscientes. Ela é constantemente presente [na vida humana] como uma atmosfera"52.

Essas passagens mostram-nos que, ainda fosse possível identificar aspectos do conceito freudiano de eu-corpo na fenomenologia do corpo próprio, teríamos necessariamente de reavaliar essa noção sob a perspectiva merleau-pontiana da sexualidade. Infelizmente, Merleau-Ponty não examinou na Fenomenologia da Percepção mais detidamente as teorias freudianas do aparelho psíquico e das pulsões, deixando completamente de lado, por exemplo, a instância psíquica do isso. No entanto, ao deslocar o centro da sexualidade das representações inconscientes para a tese de uma "atmosfera", tudo indica que ele estava disposto a reformular um dos eixos fundamentais da psicanálise pelo olhar fenomenológico. Além disso, Merleau-Ponty propôs, ainda que brevemente, uma concepção de tratamento psicanalítico que enfatiza o engajamento presente, em coexistência com o analista.

Assumindo um presente, eu recupero e transformo meu passado, eu mudo o seu sentido, eu me liberto, me desprendo dele. O tratamento psicanalítico não cura provocando uma tomada

51 Ibidem, p. 852. Tradução nossa.

52 Ibidem, p. 854. Tradução nossa. 
de consciência do passado, mas de início ligando o sujeito ao seu médico por novas relações de existência. Não se trata de dar à interpretação um assentimento científico e de descobrir um sentido nocional do passado, trata-se de re-viver como significante isto ou aquilo, e o doente só o alcança vendo seu passado na perspectiva da sua coexistência com o médico ${ }^{53}$.

Nesse sentido, a abordagem fenomenológica do corpo próprio em Merleau-Ponty oferece pontos de contato com a noção de eu-corpo freudiana, mas exigiria uma reformulação de duas questões psicanalíticas fundamentais: a teoria da sexualidade e a metodologia clínica. Talvez por essa razão a concepção merleau-pontiana de inconsciente tenha sido evitada e criticada por importantes psicanalistas ${ }^{54}$.

Vejamos, ainda, um segundo feixe de implicações que o desenvolvimento da perspectiva fenomenológica de corpo próprio pode ter para a psicanálise, a partir do pensamento de Michel Henry. A fenomenologia do corpo de Michel Henry toma um ponto de partida diferente de Merleau-Ponty, por influência da ontologia de Maine de Biron, e é fazendo uma crítica ao problema da passividade no pensamento desse filósofo que Henry propõe uma teoria ontológica da carne (chair). ${ }^{55}$ Mais tarde, em Encarnação - uma filosofia da carne, Michel Henry escreve algumas páginas sobre o erotismo, ${ }^{56}$ mas como bem assinala Cristophe Dejours a respeito, “[...] aí, a discussão tem como interlocutores principais Schopenhauer e Kierkegaard, e deixa de lado Freud". ${ }^{57}$ Como o fenomenólogo da carne compreendeu a psicanálise?

\footnotetext{
53 Ibidem, p. 1161. Tradução nossa.

54 No livro Maurice Merleau-Ponty et la psychanalyse - La consonance imparfaite, Thamy Ayouch mostra como Pontalis, André Green, Jacques Lacan e Castoriadis sinalizaram para a proximidade entre Merleau-Ponty e a psicanálise, mas ofereceram críticas às limitações de uma perspectiva fenomenológica do inconsciente. (AYOUCH, Thamy. Maurice Merleau-Ponty et la psychanalyseLa consonance imparfaite. Paris: Le Bord de l'eau, 2012 apud SILVA, Claudinei Aparecido de Freitas. Merleau-Ponty, fenomenologia e psicanálise. Trans/Form/Ação, v. 37, n. 1, p. 257-262, 2014).

55 HENRY, Michel. Philosophie et phénoménologie du corps. Paris: PUF, 1965. Tradução nossa.

${ }^{56}$ HENRY, Michel. Incarnation - Une philosophie de la chair. Paris: Seuil, 2000, p. 298-317.

57 DEJOURS, Christophe. "O corpo entre psicanálise e fenomenologia da vida”, op. cit., p. 197. Tradução nossa.
} 
Se quisermos, efetivamente, compreender a perspectiva que Michel Henry desenvolveu sobre a psicanálise, temos de nos voltar para o livro Genealogia da psicanálise. Nesse livro, Michel Henry faz um enorme esforço de interpretar a obra de Freud sob a perspectiva da tradição filosófica, traçando uma linha de abordagem que passa por Descartes, Kant, Schopenhauer e Nietzsche. Em seu último capítulo, Michel Henry propõe uma revisão crítica da noção de inconsciente em Freud. O objetivo de Michel Henry é mostrar o estatuto do afeto na psicanálise como ponto chave para o entendimento do inconsciente.

Resta o essencial do pensamento de Freud: o representante da pulsão não é somente a representação, ele é também o afeto. Nesse encontro, enfim, com o fundo do inconsciente e da vida, a psicanálise vai nos revelar o seu segredo ${ }^{58}$.

Qual seria esse segredo? Entre as vacilações e pressuposições da psicanálise, estaria a dissociação entre psique e fenomenalidade. Entretanto, o afeto não seria apenas um representante da pulsão, ele constituiria o seu fundamento. "Ora, o afeto não é inconsciente e não pode sê-lo, nem por consequência tornar-se", 59 de forma que a conclusão a que se chega é que "o fundo do inconsciente não é, enquanto afeto, nada de inconsciente" ${ }^{\text {"60 }}$. Ou seja, se o afeto não é jamais inconsciente e é a representação que sucumbe ao recalcamento, então é somente a representação (e não o sentimento) que se torna inconsciente. O recalcamento não significaria um desaparecimento do afeto, nem por consequência da fenomenalidade que lhe pertence por princípio, "mas somente sua modalização em um outro afeto e finalmente em angústia"61.

O gesto de Henry recupera o papel do afeto da psicanálise em diálogo com uma abordagem fenomenológica e, sem negar a natureza pulsional da

\footnotetext{
58 HENRY, Michel. Généalogie de la psychanalyse. Paris: PUF, 1985, p. 368-369. Tradução nossa.

59 Ibidem, p. 369. Tradução nossa.

60 Ibidem. Tradução nossa.

${ }^{61}$ Ibidem, p. 371. Tradução nossa.
} 
libido como um excitante interno ou autoexcitação, reporta a psicanálise à uma fenomenologia da vida.

A vida é pulsão, a libido; a angústia é o sentimento da libido, a prova que a libido faz ela mesma não enquanto essa libido particular, mas enquanto encurralada em si, em sua incapacidade de romper a ligação que a liga a ela mesma ${ }^{62}$.

Em outros termos, ao revisar o tema do afeto em psicanálise, tendo como arcabouço teórico a fenomenalidade do corpo próprio, Michel Henry contribui para a compreensão de como o eu se constitui pela via perceptiva, ao mesmo tempo em que experimenta a dimensão endógena da vida pulsional e entra em contato com o recalcamento operado pelo supereu. Sua perspectiva influenciou e se faz sentir em elaborações recentes da psicanálise que recuperaram o estatuto do corpo. É o que percebemos na abordagem do corpo de Christophe Dejours.

[...] nas relações entre o funcionamento mental e o funcionamento biológico, o corpo inteiro está envolvido, não somente o cérebro. $O$ problema das relações entre corpo e mente não se limitaria, pois, àquele da relação entre pensamento e cérebro, como tantas vezes se afirmou, ainda mais insistentemente com o avanço recente da psiquiatria dita biológica ${ }^{63}$.

A nossa hipótese parece se confirmar pela análise de dois grandes mestres da fenomenologia do corpo próprio, Maurice Merleau-Ponty e Michel Henry. Nossa pretensão não foi estabelecer uma leitura única ou

\footnotetext{
62 Ibidem, p. 379. Tradução nossa.

${ }_{63}$ DEJOURS, Christophe. Primeiro, o corpo - Corpo biológico, corpo erótico e senso moral. Trad.: Vanise Dresch. Porto Alegre: Dublinense, 2019 (2003), p. 22. Não poderemos aqui explorar o modo como Dejours dialoga com Laplanche e propõe uma leitura inovadora sobre a psicossomática, além de estabelecer o que ele intitula uma "terceira tópica", com a noção de "inconsciente amencial".
} 
definitiva sobre o estatuto do corpo na psicanálise, mas mostrar como justamente a noção de eu-corpo em $O$ eu e o isso, a nosso juízo pouco explorada por Freud ele mesmo, apresenta um horizonte promissor de diálogo com a fenomenologia, que está longe de ser fechado.

\section{Considerações finais}

Traçamos um percurso de aproximação da psicanálise com a fenomenologia por entre a interrogação da viabilidade desse encontro, sendo que alguns esforços já foram tentados por importantes autores nesse sentido. Embora a interrogação permaneça - e nossa intenção não era dissolver o problema -, acreditamos ter encontrado pelo menos uma via de desenvolvimento possível de um diálogo frutífero dessa tensa aproximação. Nossa hipótese partiu da psicanálise freudiana visando ao encontro da fenomenologia por meio de uma noção pouco explorada por Freud, porém de importância capital: a noção de eu-corpo tal como aparece em O eu e o isso.

Em um primeiro momento, tentamos mostrar como Freud deixa transparecer nessa obra, ainda que de modo lateral, o seu entendimento sobre a psicologia de Brentano e o desenvolvimento posterior da fenomenologia, posicionando-se em relação a elas. Em seguida, tomamos a direção que o próprio Freud aponta da importância do isso na reformulação da primeira tópica. Assim, resgatando as origens da noção de isso, foi possível compreender como tal reformulação também alterou o seu entendimento do corpo. O intercâmbio intelectual entre Freud e Groddeck mostrou-se importante para o formulador da psicanálise na medida que forneceu a esse um entendimento das forças atuantes no inconsciente e da importância do isso para a noção de eu e do corpo. Nessa obra freudiana, o corpo não aparece como mero aparelho fisiológico, ainda que a dimensão biológica Ihe seja também constitutiva, mas relacionado ao eu sem reduzir-se a este.

Compreendemos, do modo como Freud expõe a relação do eu com o corpo nessa obra, que o eu se caracteriza, por um lado, através da senso-percepção e da motricidade, assim como, por outro lado, a partir de um processo mental 
de projeção sobre a superfície do corpo. Com isso, o eu não se mostra mais como uma instância "abstrata", uma "substância" ou uma "coisa"; mas como uma instância psíquica resultante de um processo contínuo de contato com o mundo externo através das percepções. O eu apresenta-se mediando as tensões e os estímulos externos e internos, e nesse processo atribui identidade a si, na forma de uma consciência corpórea de si. Desse modo, compreendemos que não há constituição do eu sem a percepção do corpo próprio.

Pudemos notar que o eu-corpo freudiano pode corresponder em vários aspectos ao que foi chamado em fenomenologia de corpo próprio e, assim, passamos a examinar a abordagem de dois fenomenólogos que trataram profundamente do corpo próprio, Maurice Merleau-Ponty e Michel Henry. Com esse exame, aspiramos à confirmação de nossa hipótese de que a noção de corpo próprio pavimenta um diálogo promissor entre a psicanálise e a fenomenologia, embora não sem implicações e pontos de tensão para a psicanálise. O tratamento que Merleau-Ponty dá para a noção de corpo próprio permite muitos elementos de contato com a noção de eu-corpo freudiano, porém, para avançar nesse caminho de aproximação, haveria de realizar-se uma profunda revisão da teoria da sexualidade freudiana, além de sua metodologia clínica. O tratamento que Michel Henry dá para o corpo contribui para a compreensão da concepção freudiana da constituição do eu pela via perceptiva; mas, ao esclarecer como isso se dá, reconduz a psicanálise a uma fenomenologia da vida. A implicação para a psicanálise, nesse caso, é ter de revisar o tema do afeto como questão central para a compreensão do inconsciente.

Por fim, parece-nos que nossa hipótese da possibilidade de encontro da psicanálise com a fenomenologia via noção de eu-corpo de Freud, em O eu e o isso, é confirmada. Juntamente com esse entendimento, também pudemos compreender que, para avançar nessa aproximação, isso significaria recolocar certas teses centrais da psicanálise em um novo rumo. Sem dúvidas, o diálogo da filosofia com a psicanálise e vice-versa ainda é um campo profícuo e, a nosso juízo, pouco explorado. 


\section{Referências}

ANZIEU, D. Le moi-peau. 2. ed. Paris: Dunod, 1995.

ASSOUN, P-L. Freud e Nietzsche: semelhanças e dessemelhanças. São Paulo: Brasiliense, 1989.

AYOUCH, T. Maurice Merleau-Ponty et la psychanalyse: la consonance imparfaite. Paris: Le Bord de l'eau, 2012.

BRENTANO, F. Psychologie vom Empirischen Standpunkte. Leipzig: Dunker \& Humblot, 1874.

CATALDO-MARIA, T. M. S.; WINOGRAD, M. Freud, Brentano e a Concomitância dependente. Psicologia: Teoria e Pesquisa, Brasília, v. 33, p. 1-9, 2017. https:// doi.org/10.1590/0102.3772e3347

CATALDO-MARIA, T. M. S.; WINOGRAD, M. Freud e Brentano: mais que um flerte filosófico. Psico, Porto Alegre, v. 44, n. 1, p. 34-44, 2013.

DEJOURS, C. O corpo entre psicanálise e fenomenologia da vida. In: ANTÚNEZ, A. E. A.; MARTINS, F.; FERREIRA, M. V. Fenomenologia da vida em Michel Henry: interlocução entre filosofia e psicologia. Tradução de Isabelle Gayon. São Paulo: Escuta, 2014. p. 197-226. https://doi.org/10.1590/0103-6564d20150008

DEJOURS, C. Primeiro, o corpo: corpo biológico, corpo erótico e senso moral. Tradução de Vanise Dresch. Porto Alegre: Dublinense, 2019.

FINK, E. Finks Beilage zum Problem des 'Unbewußtes'. In: HUSSERL, E. Die Krisis der europäischen Wissenschaften und die Transzendentale Phänomenologie. 2. Aufl. The Hague: Martinus Nijhoff, 1962. https://doi.org/10.1007/97894-010-1335-2

FREUD, S. Abriss der Psychoanalyse. London: Imago, 1941. (Gesammelte Werke, v. 17). p. 63-138.

FREUD, S. Bruchstück einer Hysterie-Analyse. Leipzig: Internationaler Psychoanalytischer, 1924. bd. 8.

FREUD, S. Das Ich und das Es. Frankfurt: Fischer, 1975. (Studienausgabe, bd. 3). FREUD, S. Triebe und Triebschicksale. Frankfurt: Fischer, 1975. (Studienausgabe, bd. 3).

FREUD, S.; SALOMÉ, L. A. Correspondência completa. Tradução de Dora Flacksman. Rio de Janeiro: Imago, 1975.

GRODDECK, G. Das Buch vom Es. Leipzig: Internationaler Psychoanalytischer, 1923. 
GRODDECK, G. Der gesunde und kranke mensch (Nasamecu). Leipzig: Hirzel, 1913. HENRY, M. Généalogie de la psychanalyse. Paris: PUF, 1985.

HENRY, M. Incarnation: une philosophie de la chair. Paris: Seuil, 2000.

HENRY, M. Philosophie et phénoménologie du corps. Paris: PUF, 1965.

HUSSERL, E. Die Krisis der europäischen Wissenschaften und die Transzendentale Phänomenologie. 2. Aufl. The Hague: Martinus Nijhoff, 1962. bd. 6. https:// doi.org/10.1007/978-94-010-1335-2

HUSSERL, E. Grenzprobleme der Phänomenologie: Analysen des Unbewußtseins und der Instinkte. Metaphysik. Späte Ethik. New York: Springer, 2014. https:// doi.org/10.5840/studphaen20151525

LE VAGUERĖSE, L. Introdução à obra de Groddeck. In: NASIO, J-D. Introdução às obras de Freud, Ferenczi, Groddeck, Klein, Winnicott, Dolto, Lacan. Rio de Janeiro: Zahar, 1995. p. 103-132.

LOPARIC, Z. Theodor Lipps: uma fonte esquecida do paradigma freudiano. Natureza Humana, São Paulo, v. 3, n. 2, p. 315-331, 2001.

MARTYNKEWICZ, W. Georg Groddeck: Eine Biographie. Frankfurt: Fisher, 2015. MERLEAU-PONTY, M. Le visible et l'invisible. Paris: Gallimard Quarto, 2010. MERLEAU-PONTY, M. Phénoménologie de la perception. Paris: Gallimard Quarto, 2010.

SARTRE, J-P. L'homme au magnétophone. Paris: Gallimard, 1972. (Situations, v. 9).

SARTRE, J-P. Sartre par Sartre. Paris: Gallimard, 1972. (Situations, v. 9).

SARTRE, J-P. L'Être et le Néant: essai d'ontologie phénoménologique. Paris: Gallimard, 1943.

SILVA, C. A. F. Merleau-Ponty, fenomenologia e psicanálise. Trans/Form/ Ação, Marília, v. 37, n. 1, p. 257-262, 2014. https://doi.org/10.1590/s010131732014000100014

SILVA, M. C. C. O. O legado de Georg Groddeck: genuinidade e originalidade. 2009. Dissertação (Mestrado em Psicossomática e Psicologia Hospitalar) Pontifícia Universidade Católica de São Paulo, São Paulo, 2009. https://doi. org/10.5327/z1984-4840201626302

STEIN, E. Anamnese: a filosofia e o retorno do reprimido. Porto Alegre: EdiPUCRS, 1997. 
VANASSI, F. B. Do eu-pele ao corpo próprio: corporeidade e subjetividade em Anzieu e Merleau-Ponty. 2017. Dissertação (Mestrado em Psicologia Clínica) - Programa de Pós-Graduação em Psicologia, Departamento de Psicologia, Centro de Teologia e Ciências Humana, Pontifícia Universidade Católica do Rio de Janeiro, Rio de Janeiro, 2017. https://doi.org/10.17771/pucrio.acad.30538

\section{Endereço postal}

\section{Fabio Caprio Leite de Castro}

Escola de Humanidades da PUCRS

Avenida Ipiranga 6681 - Prédio $8-4^{\circ}$ Andar

Partenon, Porto Alegre - RS, 90619-900 